\title{
IMPACT OF ALCOHOL INTOXICATION AND WITHDRAWAL SYNDROME ON SOCIAL PHOBIA AND PANIC DISORDER IN ALCOHOLIC INPATIENTS
}

\author{
Mauro Barbosa Terra, Ivan Figueira and Helena Maria Tannhauser Barros
}

TERRA MB et al. Impact of alcohol intoxication and withdrawal syndrome on social phobia and panic disorder in alcoholic inpatients. Rev. Hosp. Clín. Fac. Med. S. Paulo 59(4):187-192, 2004.

PURPOSE: To investigate the impact of alcohol intoxication and withdrawal on the course of social phobia and panic disorder.

METHOD: A group of 41 alcoholic inpatients undergoing detoxification therapy were interviewed using the SCID-I (DSM-IV) and questions to detect fluctuations in the course of social phobia and panic disorder as a function of the different phases in alcohol dependence (intoxication, withdrawal, and lucid interval).

RESULTS: Only 1 (2.4\%) patient presented panic disorder throughout life, and 9 (21.9\%) had panic attacks during alcohol intoxication or during the withdrawal syndrome. Sixteen (39\%) alcoholic patients showed social phobia with onset prior to drug use. However, drinking eventually became unable to alleviate social phobia symptoms or worsened such symptoms in $31.2 \%$ of social-phobic patients. While patients with social phobia reported a significant improvement in psychiatric symptoms during alcohol intoxication, patients experiencing panic attacks worsened significantly during intoxication. In the withdrawal phase, patients with social phobia tended to have more and more intense phobic symptoms.

CONCLUSION: Our findings indicate that the impact of alcohol intoxication is different for social phobia as compared to panic disorder, at first decreasing the social-phobic symptoms but later aggravating them. In panic disorder, the impact of intoxication by alcohol is more harmful, at least in the short term.

KEY WORDS: Social phobia. Panic disorder. Intoxication. Withdrawal. Alcohol abuse.

Alcohol-dependent patients have a higher prevalence of anxiety disorders than the general population. On the other hand, patients with anxiety disorders have higher prevalence of abuse and/or dependence on alcohol and other drugs than the general population. ${ }^{1}$ The order of emergence of these comorbidities, however, is not clear. One of the reasons for this may be the existence of different clinical syndromes comprising anxiety disorder.

Several studies have shown that there is a strong association between alcohol abuse and social phobia and a high frequency of alcoholism among social phobic patients. ${ }^{2-16}$ Patients with social phobia have twice as many alcohol-related problems as those who are not phobic, and individuals with drinking-related disorders are 9 times more likely to have social phobia than the general population. ${ }^{16,17}$ There is, as well, a high rate of panic-related disorders among alcoholics, ${ }^{18-21}$ and sev-

From the Department of Psychiatry and Forensic Medicine, Fundação Faculdade Federal de Ciências Médicas of Porto Alegre - Porto Alegre/RS, Brazil and the Psychiatry Institute of the University of Brazil, Federal University of Rio de Janeiro - Rio de Janeiro/ RJ, Brazil.

E-mail: mabarte@portoweb.com.br Received for publication on January 21, 2004. eral investigators have found high rates of alcohol abuse among patients with panic disorder. ${ }^{12,22,23}$

The chronological relationship between panic disorder or social phobia and alcohol dependence is controversial, with some studies showing that panic attacks precede the abuse and/ or alcohol dependence in more than $50 \%$ of the patients, ${ }^{11,24}$ while in other studies, panic attacks are detected following abuse and/or alcohol addiction. ${ }^{19,25,26,27}$ On the other hand, social phobia typically precedes problems with alcohol, ${ }^{1}$ predisposing the affected individuals to a higher vulnerability to addictive disorders. ${ }^{28,29}$ 
In this sense, drug use may be a form of self-medication, but few studies report the impact of alcohol intoxication or alcohol withdrawal on the clinical course of these anxiety disorders. Thus, we have investigated the comorbidity of panic disorder or social phobia and alcohol addiction concerning the frequency and order of onset of the different disorders, ie,

the time relationship between the beginning of the anxiety disorder and the emergence of alcohol dependence, with the objective of comparing the effect of the phases of alcohol intoxication and withdrawal on the symptoms of social phobia and panic disorder.

\section{METHOD}

Forty-nine inpatients undergoing treatment of alcohol dependence in a psychiatric clinic in Porto Alegre were consecutively examined during a period of 8 months. The following exclusion criteria were used: psychotic symptoms, including delusions or hallucinations; schizophrenia; bipolar disorder, mental retardation; and confusional states. Eight patients were thus excluded, and the final sample comprised 41 patients.

Patients fulfilled the DSM-IV diagnostic criteria for alcohol dependence as well as those of CID-10. All patients were administered the SCID-I, a semistructured interview based on APA1994 DSM-IV, to determine the presence of panic disorder and social phobia. In addition, questions were formulated to describe the order of onset for the different comorbidities with respect to drinking to determine if there was an attempt at self-medication, and the effect of drinking or withdrawal on the symptoms of social phobia or panic disorder was assessed. Patients were interviewed after being in the hospital and undergoing withdrawal from any drug for at least 7 days.
The association between categorical variables was assessed using the chi-square test or the Fisher's exact test when the former did not meet the necessary demands. Results were generated with the help of the statistical package SPSS (Statistical Package for the Social Sciences) for Windows. The results were considered significant at $P<.05$.

This study was approved by the Research Ethics Board of the clinic, and all participants gave their informed consent in written form.

\section{RESULTS}

Table 1 shows the clinical and sociodemographic characteristics of the participants. As can be seen, most of the patients of the sample completed high school and were male, married, and working. While 21 patients $(51.2 \%)$ were dependent on alcohol, only 20 patients $(48.8 \%)$ used multiple drugs. Table 2 lists the types of drugs used and the number of patients who had anxiety symptoms. Among patients using multiple drugs,

Table 1 - Clinical and sociodemographic characteristics of the alcoholic inpatients.

\begin{tabular}{ll}
\hline Variable & Number \\
\hline Sex & \\
$\quad$ male & $35(85.4 \%)$ \\
$\quad$ female & $6(14.6 \%)$ \\
Marital status & \\
$\quad$ married & $17(41.4 \%)$ \\
$\quad$ single & $15(36.6 \%)$ \\
$\quad$ divorced & $2(4.9 \%)$ \\
$\quad$ separated & $6(14.6 \%)$ \\
$\quad$ idowed & $1(2.4 \%)$ \\
Schooling & \\
$\quad$ elementary school (complete or incomplete) & \\
$\quad$ high school (complete or incomplete) & $10(24.4 \%)$ \\
$\quad$ university (complete or incomplete) & $21(51.2 \%)$ \\
Ocupational status & $10(24.4 \%)$ \\
$\quad$ working & \\
not working & \\
Age (mean \pm SD) & $26(63.4 \%)$ \\
Number of hospitalizations (mean \pm SD) & $15(36.6 \%)$ \\
\hline
\end{tabular}

Table 2 - Drugs used and anxiety disorders among alcoholic inpatients being treated for alcohol dependence.

\begin{tabular}{lcccc}
\hline Type of drug & $\begin{array}{c}\text { Number of } \\
\text { patients }\end{array}$ & $\begin{array}{c}\text { Patients with } \\
\text { panic attacks/ } \\
\text { disorder }\end{array}$ & $\begin{array}{c}\text { Patients with } \\
\text { social phobia }\end{array}$ & $\begin{array}{c}\text { Patients without } \\
\text { panic attacks/ } \\
\text { disorder or } \\
\text { social phobia }\end{array}$ \\
\hline alcohol & $21(51.2 \%)$ & 3 & 11 \\
$\begin{array}{l}\text { alcohol, marijuana, } \\
\text { and cocaine }\end{array}$ & $10(24.4 \%)$ & 6 & 5 & 1 \\
$\begin{array}{l}\text { alcohol and } \\
\text { cocaine }\end{array}$ & $8(19.5 \%)$ & 1 & 2 & 6 \\
$\begin{array}{l}\text { alcohol and } \\
\text { marijuana }\end{array}$ & $1(2.4 \%)$ & 0 & 0 & 1 \\
$\begin{array}{l}\text { alcohol and } \\
\text { benzodiazepine }\end{array}$ & $1(2.4 \%)$ & 0 & 0 & 1 \\
\hline
\end{tabular}


$18(43.9 \%)$ used cocaine, $11(26.8 \%)$ marijuana, and $1(2.4 \%)$ benzodiazepines, but no differences were detected between the drugs used and the diagnoses of anxiety disorders.

\section{Occurrence of Panic Disorder}

Although 10 patients reported having panic attacks $(24.4 \%)$, only 1 $(2.4 \%)$ of these patients actually had panic disorder. Among the 9 patients (21.9\%) who did not have panic disorder, the attacks occurred during intoxication or as part of the withdrawal syndrome. Panic attacks were not reported to occur in other than these 2 situations. Of the 10 patients who presented panic attacks, 7 (70\%) had attacks in the intoxication phase and 6 $(60 \%)$ during alcohol withdrawal. Therefore only 1 patient in the sample suffered from panic disorder, and $21.9 \%$ had panic-like symptoms, having attacks secondarily to the use of alcohol (Table 3).

\section{Occurrence of Social Phobia}

Of the 41 patients interviewed, 16 (39\%) had social phobia. Among these patients, social phobia started before the onset of alcohol dependence. Con- cerning the impact of drinking on social phobic symptoms, 11 (68.7\%) patients reported improvement in social phobia during intoxication, while the other $31.2 \%$ did not notice this effect. There was a worsening of social phobia during the withdrawal from alcohol in all these patients, and they presented social-phobic symptoms again after a prolonged period of alcohol withdrawal. (Table 3).

In the case of patients for whom drinking reduced social phobia, there was no development of tolerance to these effects in the intoxication phase. These patients reported maintenance of the benefit of drinking for social phobia, with improvement in the social phobia when they were intoxicated. Of these patients, 4 mentioned that they deliberately drank to alleviate phobic symptoms. The following case illustrates this point:

V.R., 24 years of age, male, single, incomplete high school, military

The patient reported having phobic symptoms since childhood. He started drinking harmfully at the age of 17 , which increased over the years. After 7 years of drinking, he is dependent on alcohol. He reports improvement in social phobia when he drinks, and it worsens during with-

Table 3 - Effects of drinking on anxiety symptoms in alcoholic inpatients.

\begin{tabular}{lll}
\hline & Panic attacks/disorder & Social phobia \\
\hline Frequency & $10(24.4 \%)$ & $16(39 \%)$ \\
$\begin{array}{l}\text { Chronological relation } \\
\text { onset before drug use } \\
\text { onset after drug use }\end{array}$ & $1(10 \%)$ & $16(100 \%)$ \\
& $9(90 \%)$ & $0(0 \%)$ \\
$\begin{array}{l}\text { During intoxication } \\
\quad \text { improves* }\end{array}$ & $0(0 \%)$ & $11(68.7 \%)$ \\
$\quad$ worsens* & $3(70 \%)$ & $3(18.7 \%)$ \\
$\quad$ not affected & $3(30 \%)$ & $2(12.5 \%)$ \\
During withdrawal & & $0(0 \%)$ \\
$\quad$ improves & $0(0 \%)$ & $16(100 \%)$ \\
$\quad$ worsens* & $6(60 \%)$ & $0(0 \%)$
\end{tabular}

\footnotetext{
* Denotes significant differences $(P<.05)$ between patients with panic symptoms and those
} with social phobia drawal. Thus, the patient suffers from social phobia preceding alcohol use. He uses alcohol as a form of self-medication to reduce phobia, and even today, he still derives benefits from this use.

Another $31.2 \%$ of this group of social-phobic patients who currently get worse or do not experience any benefit during the intoxication phase have developed tolerance to the "therapeutic" effects of alcohol. They reported having lost the beneficial effects of alcohol on social phobia, the symptoms of which used to improve during the early stages of drinking. Today, 3 $(18.7 \%)$ of these patients experience worsening of social phobia when they drink, and 2 (12.5\%) patients noticed that they have lost the beneficial effect of drinking on social phobia but drink anyway, even being aware of their worsening social phobia. The following case illustrates these cases:

G.B., a 48-year-old male, married, incomplete high school, retired bank clerk.

The patient reported having begun to notice phobic symptoms at 12 years of age. He is now dependent on alcohol and reported having started to drink more heavily at 17 years of age. He began to have panic attacks 18 months before the interview, always when intoxicated with alcohol. The patient thus has had panic attacks induced by alcohol, but he does not fulfill the criteria for panic disorder. $\mathrm{He}$ suffers from social phobia, which started before he began drinking and improved as he drank, with phobic symptoms returning during alcohol abstinence. Today, however, drinking does not reduce his phobic symptoms as effectively as it used to.

\section{Comparison of drug effects on the symptoms of social phobia and panic}

According to the patients' reports, the impact of alcohol intoxication dif- 
fered in individuals with social phobia or panic, with statistically significant differences occurring when these 2 groups of patients were compared. While $68.7 \%$ of patients with social phobia reported improvement in their symptoms during heavy drinking, no patient with panic reported alleviation of symptoms during the intoxication period (Fisher's exact test, $P=0.001$ ). As for the worsening of anxiety during the intoxication phase, the relationship was an opposite one as well: $70 \%$ of patients with panic reported worsening of symptoms versus $18.7 \%$ of social-phobic patients (Fisher's exact test; $P=0.015)$. Thus, the patients with social phobia showed a significant improvement in the alcohol intoxication phase as compared to patients with panic attacks, who worsened significantly.

While $100 \%$ of patients with social phobia reported worsening of symptoms during the withdrawal phase, $60 \%$ of patients with panic reported intensification of panic attacks (Fisher's exact test, $P=0.014)$. Thus, the patients with social phobia had a statistically significant worsening during withdrawal as compared to the patients with panic attacks. None of the patients with phobia or panic reported improvement of anxiety symptoms during withdrawal (Table 3).

\section{DISCUSSION}

In this sample, panic attacks tended to occur following the abuse of alcohol. While this finding is in agreement with some studies, ${ }^{19,25-27}$ it is in disagreement with others ${ }^{11,24}$ which show that panic disorder can precede the abuse and/or dependence on alcohol in more than $50 \%$ of the patients. This difference can be ascribed to the characteristics of our sample, composed mostly of male alcoholic inpatients. Females accounted for only
$15 \%$ of the total patients in this sample. Previous research shows that panic disorder usually begins before alcohol dependence among females, and that among males, alcoholism and use of other drugs tend to precede an anxiety disorder, triggering panic. ${ }^{24,30}$ This difference between males and females may have clinical implications.

On the other hand, few previous studies have found such a low percentage of panic disorder as this one $(2.4 \%)$ in samples of alcohol-dependent patients. This may be because most studies classify all patients that have panic attacks in the category of panic disorder, including when those attacks are secondary to drinking. If we use this definition in our study, the frequency of panic disorder would be close to that found in the literature ${ }^{-}$around $24 \%$ of patients. ${ }^{18-21}$

The percentage of social-phobic patients was above one third of this sample. This seems like a high rate, but it is close to those found in other investigations, ${ }^{8,9}$ and it indicates a high prevalence of comorbidity of social phobia with alcohol dependence. In all 16 patients, social phobia preceded alcohol dependence, a finding that is consistent with the hypothesis of selfmedication, i.e. the use of alcohol to "treat" social phobia. ${ }^{1}$ Anxiety disorders such as phobias seem to have an early onset, predisposing individuals to addictive disorders, ${ }^{29}$ with much evidence that alcohol abuse is an attempt to self-medicate in a considerable number of social-phobic individuals. $^{31}$

These data are important for future evaluations concerning the treatment of anxiety disorders and alcoholism. There is evidence that patients with a dual diagnosis of alcoholism and any mental disorder have different therapeutic needs than patients with a single diagnosis, ${ }^{32}$ because they have a lower response rates to the therapy for their mental disorder as well as more severe psychiatric symptoms. When social phobia is associated with abuse/ dependence on alcohol, the effectiveness of treatment with tranylcypromine is decreased, ${ }^{33}$ and there is an increase in suicide attempts in patients with panic disorder associated with alcohol abuse. $^{34}$

A new approach in this study was the attempt to describe the effect of drug use on anxiety symptoms (panic disorder and social phobia), during the intoxication and withdrawal phases and during lucid intervals, or prolonged periods without drinking, in alcoholic inpatients. One of the most significant findings was that in a few cases, drinking had eventually lost its ability to reduce the social-phobic symptoms, characterized by the development of tolerance and even worsening these phobic symptoms. The patients who developed tolerance continued to drink even after having lost the benefit on social phobia initially sought in drinking, since they had developed dependence. However, different courses of the phobia-drinking relationship can be seen in this group of patients. A few phobic patients initially improved with drinking, but after years of drinking they became worse during alcohol intoxication. This finding supports the existence of a "paradoxical" phenomenon after medium/long-term alcohol use. Although the patients in this group whose social phobia got worse with drinking were few, the incidence might be higher in cases of more prolonged dependence. Therefore, the impact of drinking on social phobia seems to have 2 phases: an early, short-term phase, which leads to the alleviation of social phobic symptoms, followed by a second phase after medium or long-term alcohol use, which is associated with worsening of social-phobic symptoms as compared to baseline. This characteristic is not unique to drinking but is also characteristic of a group of 
GABAergic pharmacological agents, since benzodiazepines can, in the long run, aggravate the symptoms of social phobia. ${ }^{35}$ As yet, it is unclear whether these retrospective reports point to the notion that heavy drinking aggravates social phobia in the long run. The usual notion is that drinking would be harmful because of the risk of abuse and/or dependence on alcohol. It can now be added that the use or abuse of alcoholic drinks by social-phobic pa- tients can eventually aggravate their social phobia, because alcohol can, after medium- or long-term use, have a negative impact on the course of social phobia. It should be stressed that this study has some limitations because of the small sample size. Thus, these findings must be supported by further studies carried out with larger sample sizes.

In conclusion, this study indicates that the impact of the use and/or depend- ence on alcohol is different in social phobia as compared to panic. Phobic symptoms can initially be reduced but eventually worsen because of continuos alcohol use, something which does not happen with panic. On the other hand, the acute effects of alcohol intoxication are more deleterious in panic than in social phobia; however, during the withdrawal phase, patients with social phobia tend to get worse more often than patients with panic.

\section{RESUMO}

TERRA MB e col. Impacto das fases de intoxicação e de abstinência de álcool sobre a fobia social e o transtorno de pânico em pacientes alcoolistas hospitalizados. Rev. Hosp. Clín. Fac. Med. S. Paulo 59(4):187-192, 2004.

OBJETIVO: Estudar o impacto das fases de intoxicação e de abstinência do uso de álcool sobre o curso da fobia social e do transtorno de pânico.

MÉTODO: Um grupo de 41 pacientes hospitalizados por dependência de álcool foi entrevistado com o SCIDI (DSM-IV), adicionado de perguntas para detectar as flutuações no curso da fobia social e do transtorno do pânico em função das diferentes fases do uso da droga (intoxicação, abstinência e intervalo lúcido).

RESULTADOS: Apenas um $(2,4 \%)$ paciente, apresentou transtorno de pânico ao longo da vida e nove $(21.9 \%)$ tiveram ataques de pânico na intoxicação ou na síndrome de abstinência. Dezesseis $(39 \%)$ pacientes dependentes de álcool apresentavam fobia social, que iniciava-se antes de começar o uso de bebidas alcoólicas. No entanto, com o tempo, o álcool perdeu o efeito de aliviar os sintomas da fobia social ou piorou estes sintomas em $31.2 \%$ dos pacientes fóbicos sociais. Enquanto os pacientes com fobia social relataram uma melhora significativa dos sintomas psiquiátricos na fase de intoxicação, os pacientes com pânico pioraram significativamente na fase de intoxicação. Na fase de abstinência, os pacientes com fobia social tenderam a piorar com maior freqüência.

CONCLUSÃO: Nossos achados indicam que o impacto do álcool, na intoxicação, é diferente na fobia social, quando comparado com o pânico, diminuindo os sintomas fóbicos sociais a princípio e agravando-os posteriormente. No transtorno de pânico, o impacto da intoxicação pelo álcool é mais deletério, ao menos a curto prazo.

UNITERMOS: Fobia social. Transtorno de pânico. Intoxicação. Abstinência. Abuso de álcool.

\section{REFERENCES}

1. Lépine JP, Pélissolo A. Social phobia and alcoholism: a complex relationship. J Affect Disord 1998;50(Suppl):23-8

2. Amies PL, Gelder MG, Sham PM. Social Phobia: a comparative clinical study. Brit J Psychiatry 1983;142:174-9.

3. Barlow DH, Dinardo PA, Vermilyea BB, Vermilyea J, Shader RI. Co-morbidity and depression among the anxiety disorders issues in diagnosis and classification. J Nerv Ment Dis 1986; $174: 63-72$

4. Bibb JL, Chambless D. Alcohol use and abuse among diagnosed agoraphobics. Behav Res Ther 1986;24:49-58.
5. Thyer BA. Alcohol abuse among clinically anxious patients. Behav Res Ther 1986;24:357-9.

6. Schneier FR, Martin LY, Liebowitz MR, Gorman JM, Fyer AJ. Alcohol abuse in social phobia. J Anxiety Disord 1989;3:1523.

7. Schneier FR, Johnson J, Horning CD, Liebowitz MR, Weissman MM. Social phobia: comorbidity and morbidity in an epidemiologic sample. Arch Gen Psychiatry 1992;49:282-8.

8. Mullaney JA, Trippett CJ. Alcohol dependence and phobics: clinical description and relevance. Brit J Psychiatry 1979;135:56573 . 
9. Smail P, Stockwell T, Canter S, Hodgson R. Alcohol dependence and phobic anxiety states. I-A prevalence study. Brit J Psychiatry 1984;144:53-7.

10. Liebowitz MR, Gorman JM, Fyer AJ, Klein DF. Social phobia. Review of a neglected anxiety disorder. Arch Gen Psychiatry 1985;42:729-36.

11. Stravynski A, Lamontage Y, Lavallée YJ. Clinical phobias and avoidant personality disorders among alcoholics admitted to an alcoholism rehabilitation setting. Can J Psychiatry 1986;32:714-9.

12. Chambless DL, Cherney J, Caputto JC. Anxiety disorders and alcoholism: a study with alcoholic inpatients. J Anxiety Disord $1987 ; 1: 29-40$.

13. Norton GR, Block GW, Malan J. The psychopathology of panicking and non-panicking male alcoholics. Alcoholism Treatment Quaterly 1999;8:67-75.

14. Stockweel T, Smail P, Hodgson R, Canter S. Alcohol dependence and phobic anxiety states. II-A retrospective study. Brit J Psychiatry 1984;144: 58-63.

15. Wilson GT, Brick J, Adler J, Cocco K, Breslin C. Alcohol and anxiety reduction in female social drinkers. J Stud Alcohol 1989;50:226-35.

16. Kushner MG, Sher KJ, Beitman BD. The relation between alcohol problems and the anxiety disorders. Am J Psychiatry 1990;147:685-95.

17. Marshall JR. The diagnosis and treatment of social phobia and alcohol abuse. Bull Menninger Clin 1994;58(Suppl A):58-66.

18. Pollard CA, Detrick P, Flynn T, Frank M. Panic attacks and related disorders in alcohol-dependent, depressed, and nonclinical samples. J Nerv Ment Dis 1990;178(3):180-5.

19. Johannessen DJ, Cowley DS, Walker RD, Jensen CF, Parker L. Prevalence, onset, and clinical recognition of panic states in hospitalized male alcoholics. Am J Psychiatry 1989;146(9):1201-3.

20. Powell BJ, Penick EC, Othmer E. Prevalence of additional psychiatric syndromes among male alcoholics. J Clin Psychiatry 1982;43:404-7.

21. Hesselbrock MN, Meyer RE, Keener JJ. Psychopathology in hospitalized alcoholics. Arch Gen Psychiatry 1985;42:1050-5.

22. Boyd JH, Burke JD, Greenberg E, Holzer CE, Rae DS, George LK et al. Exclusion criteria of DSM-III: a study of cooccurrence of hierarchy free syndromes. Arch Gen Psychiatry 1984;41:983-9.
23. Katon W, Vitaliano PP, Russo J, Jones M, Anderson K. Panic disorder: spectrum of severity and somatization. J Nerv Ment Dis $1987 ; 175: 12-9$

24. Chignon JM, Lépine JP. Trouble panique et alcoolisme: influence de la comorbidité. Rev Can Psychiatrie 1993;38(7):485-93.

25. Krystal JH, Leaf PJ, Bruce ML, Charney DS. Effects of age and alcoholism on the prevalence of panic disorder. Acta Psychiatr Scand 1992;85:77-82.

26. Otto MW, Pollack MH, Sachs GS, O’Nell CA, Rosenbaum JF. Alcohol dependence in panic disorder patients. J Psychiatr Res 1992;26:29-38.

27. Schuckit MA, Hesselbrock V. Alcohol dependence and anxiety disorders: What is the relationship? Am J Psychiatry 1994;151(12):1723-34.

28. Swendsen JD, Merikangas KR, Canino GJ, Kessler RC, RubioStipec M, Angst J. The comorbidity of alcoholism with anxiety depressive disorders in four geographic communities. Compr Psychiatry 1998;39(4):176-84.

29. Regier DA, Rae DS, Narrow WE, Kaelber CT, Schatzberg AF. Prevalence of anxiety disorders and their comorbidity with mood and addictive disorders. Br J Psychiatry 1998;34(Supp1):24-8.

30. Kessler RC, Crum RM, Warner LA, Nelson CB, Schulenberg J, Anthony JC. Lifetime co-occurrence of DSM-III-R alcohol abuse and dependence with other psychiatric disorders in the National Comorbidity Survey. Arch Gen Psychiatry 1997;54:313-21.

31. Randall CL, Thomas S, Thevos AK. Concurrent alcoholism and social anxiety disorder: a first step toward developing effective treatments. Alcohol Clin Exp Res 2001;25(2): 210-20.

32. Attia PR. Dual diagnosis: definition and treatment. Alcoholism Treatment Quaterly 1988;5:53-63.

33. Versiani M, Mundim FD, Nardi AE, Liebowitz MRl. Tranylcypromine in social phobia. J Clin Psychopharmacol 1988;8(4):279-83.

34. Johnson J, Weissmann MM, Klerman GL. Panic disorder, comorbidity and suicide attempts. Arch Gen Psychiatry 1990;47:805-8.

35. Tyrer P. Diagnostic anomalies in social phobia. Int Clin Psychopharmacol 1996;11(Suppl 3):29-33. 